\title{
Supporting Information: Interfacing Carbon Nanotubes with Living Cells
}

Xing Chen ${ }^{1,5}$, Un Chong Tam ${ }^{1}$, Jennifer L. Czlapinski ${ }^{1}$, Goo Soo Lee ${ }^{1,5}$, David Rabuka ${ }^{1}$, Alex Zettl ${ }^{2,5^{*}}$, and Carolyn R. Bertozzi $i^{1,3,4,5 *}$

Departments of ${ }^{1}$ Chemistry, ${ }^{2}$ Physics and ${ }^{3}$ Molecular and Cell Biology, and ${ }^{4}$ Howard Hughes Medical Institute, University of California, Berkeley and ${ }^{5}$ Materials Sciences Division, Lawrence Berkeley

National Laboratory, Berkeley, CA 94720

\section{Part I-Synthetic procedure for mucin mimic glycopolymers}
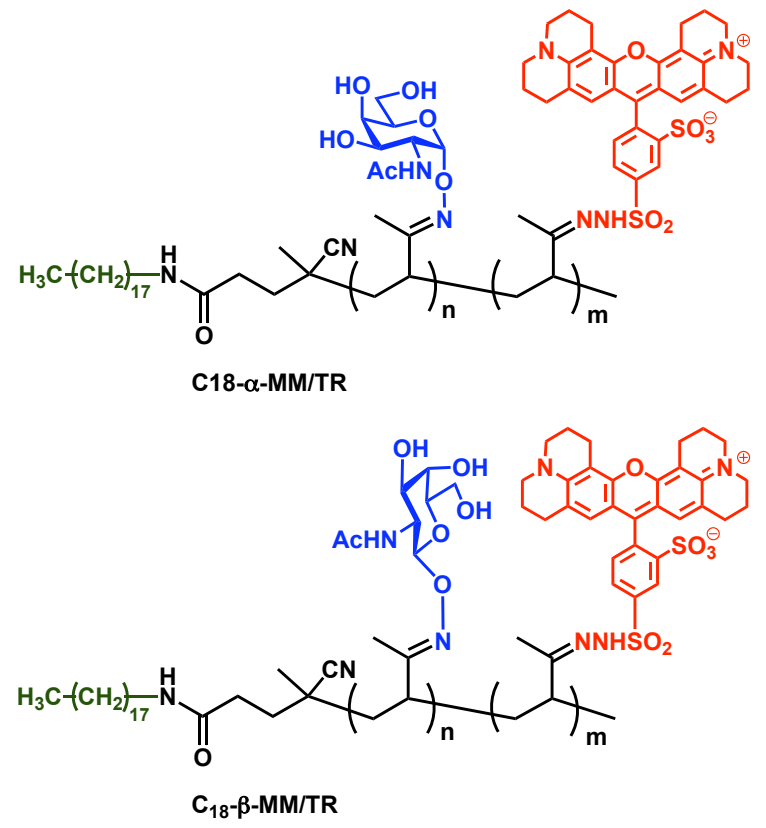

Figure S1. Structures of $\mathrm{C}_{18}-\alpha-\mathrm{MM} / \mathrm{TR}$ and $\mathrm{C}_{18}-\beta-\mathrm{MM} / \mathrm{TR}$, in which the fluorescent dye Texas Red replaced $\sim 3 \%$ of the total GalNAc residues. 
The synthetic procedure for $\mathbf{C}_{18^{-}}$terminated, $\alpha$-GalNAc-conjugated mucin mimics $\left(\mathbf{C}_{18^{-}}-\mathbf{\alpha}-\mathbf{M M s}\right)$ and $\mathbf{C}_{18^{-}}$ terminated, $\beta$-GalNAc-conjugated mucin mimic $\left(\mathbf{C}_{18}-\beta-M M\right)$ was described previously ${ }^{1}$.

$\mathrm{C}_{18}$-terminated, $\alpha$-GalNAc-conjugated mucin mimic with Texas $\operatorname{red}\left(\mathrm{C}_{18}-\boldsymbol{\alpha}-\mathrm{MM} / \mathrm{TR}\right)$ : To a solution of C18-terminated poly(MVK) ${ }^{1}(6 \mathrm{mg}, 85 \mu \mathrm{mol}$ based on number repeating carbonyl units calculated from the MW as determined by GPC) in THF $(5 \mathrm{~mL})$ and $\mathrm{H}_{2} \mathrm{O}(2 \mathrm{~mL})$ was added $\alpha$-aminooxy GalNAc ${ }^{2}(40 \mathrm{mg}, 171$ $\mu \mathrm{mol})$, texas red hydrazide $(5 \mathrm{mg}, 8 \mu \mathrm{mol})$ and acetic acid $(5 \mu \mathrm{L})$. The solution was heated to $95{ }^{\circ} \mathrm{C}$, stirred for $24 \mathrm{~h}$ and concentrated in vacuo. The resulting solid was dissolved in $\mathrm{H}_{2} \mathrm{O}(7 \mathrm{~mL})$ and refluxed for $48 \mathrm{~h}$. The reaction mixture was cooled to ambient temperature, dialyzed in $\mathrm{H}_{2} \mathrm{O}$ and lyophilized to give the product $(21 \mathrm{mg}, 77 \%$ of carbonyls reacted) as a fluffy dark red solid. IR (KBr) 3434, 1658, 1641, 1381, 1005, 557, $463 \mathrm{~cm}^{-1}$; ${ }^{1} \mathrm{H}$ NMR (400 $\mathrm{MHz}, \mathrm{D}_{2} \mathrm{O}$, see Supporting Information Figure 5); $\mathrm{GPC}\left(\mathrm{H}_{2} \mathrm{O}\right.$ eluent, polysaccharide standard), $\mathrm{M}_{\mathrm{w}}=30.9 \times 10^{3} \mathrm{Da}, \mathrm{PDI}=3.18$.

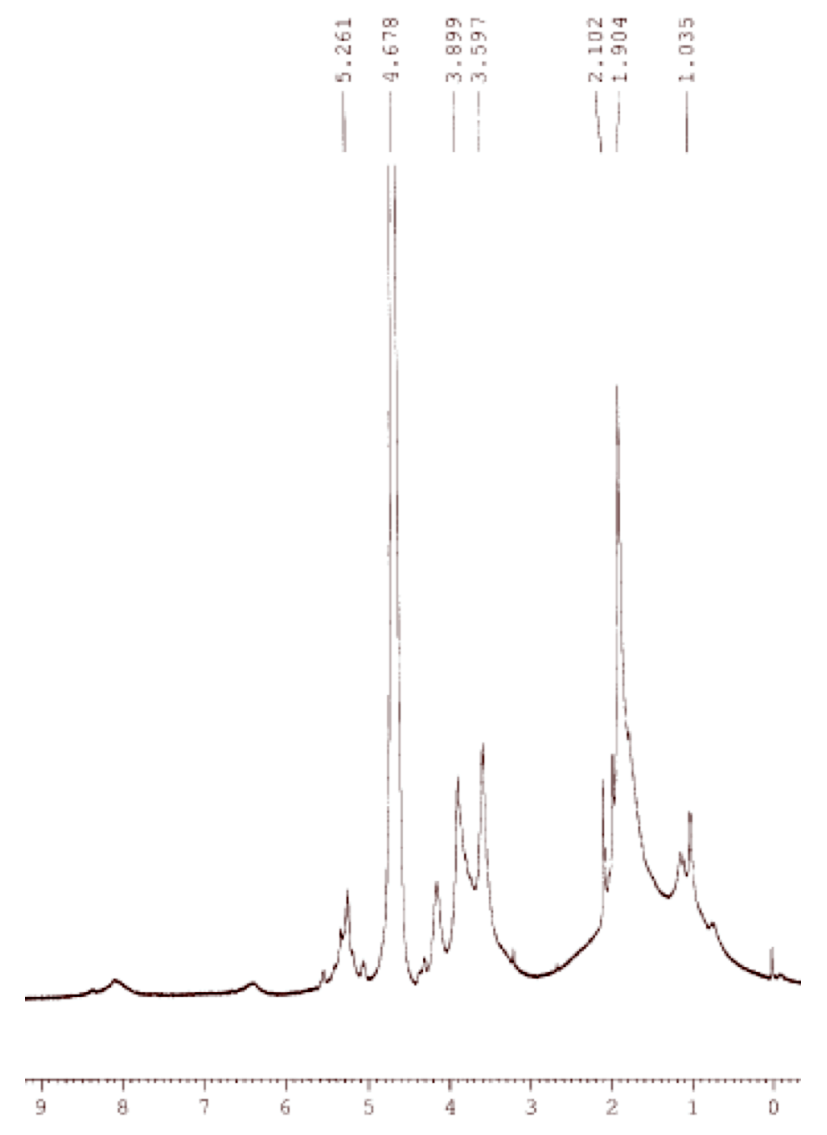

Figure S2. ${ }^{1} \mathrm{H}$ NMR of $\mathrm{C}_{18}-\alpha-\mathrm{MM} / \mathrm{TR}$

$\mathbf{C}_{18}$-terminated, $\boldsymbol{\beta}$-GalNAc-conjugated mucin mimic with Texas $\operatorname{red}\left(\mathbf{C}_{18}-\boldsymbol{\beta}-\mathbf{M M} / \mathbf{T R}\right)$ : The synthesis of $\mathrm{C}_{18^{-}}$ $\beta$-MM/TR was similar to $C_{18}-\alpha-M M / T R$. The only difference was that $\beta$-aminooxy GalNAc ${ }^{2}$ was used instead of $\alpha$-aminooxy GalNAc.

\section{Reference:}

1. Chen, X.; Lee, G. S.; Zettl, A.; Bertozzi, C. R. Angew. Chem. Int. Ed. 2004, 43, 6111-6116.

2. Marcaurelle, L. A.; Shin, Y.; Goon, S.; Bertozzi, C. R. Org. Lett. 2001, 3, 3691. 


\section{Part II---General Procedure for functionaliztion of CNTs with mucin mimic polymers}

High-purity single-walled carbon nanotubes (SWCNT) (HiPCO, $>95 \%$ ) were purchased from Carbon Nanotechnologies Inc., and high-purity multi-walled carbon nanotubes (MWNTs) (CVD, >95\%) were purchased from Nanolab. In a typical preparation experiment, $1 \mathrm{mg}$ of as-produced carbon nanotubes was suspended in 5 $\mathrm{mL}$ of aqueous $\mathrm{C}_{18}-\mathrm{MM}$ solution $(0.1 \% \sim 0.5 \%)$. The mixture was sonicated using a water-bath sonicator for $1 \mathrm{~h}$. First, insoluble material was removed by low-speed centrifugation at 3,000 x g for $30 \mathrm{~min}$, and the product suspension was decanted from the insoluble material. Then the excess free glycopolymer was removed by dialysis of the suspension in a polycarbonate membrane against deionized water for $24 \mathrm{~h}$. The resulting $\mathrm{C}_{18}-\mathrm{MM}-$ NTs $\left(C_{18}-\alpha-M M-S W N T s, \quad C_{18}-\beta-M M-S W N T s, \quad C_{18}-\alpha-M M / T R-S W N T s, \quad C_{18}-\beta-M M / T R-S W N T s, \quad C_{18}-\alpha-M M-\right.$ MWNTs, $C_{18}-\beta-M M-M W N T s, C_{18}-\alpha-M M / T R-M W N T s, C_{18}-\beta-M M / T R-M W N T s$ ) formed stable suspensions in aqueous solution. The concentrations of the resulting suspensions were calculated by evaporating the water and weighting the dried coated CNTs.

Preparation of complex of HPA-FITC bound $\mathbf{C}_{18}$-MM-CNTs (Pathway $\mathbf{I}$ in Figure 1B): Helix pomatia agglutinin conjugated with fluorescein isothiocyanate (HPA-FITC) was obtained from EY-Laboratories. A 1-mL solution of HPA-FITC $(100 \mu \mathrm{g} / \mathrm{mL})$ in buffer $(0.10 \mathrm{M}$ Tris, and $0.15 \mathrm{M} \mathrm{NaCl}, \mathrm{pH} 8.0)$ was added to the suspensions of mucin mimic-coated nanotubes $\left(\mathrm{C}_{18}-\alpha-\mathrm{MM}-\mathrm{CNTs}\right.$ or $\left.\mathrm{C}_{18}-\beta-\mathrm{MM}-\mathrm{CNTs}\right)$ in $\mathrm{H}_{2} \mathrm{O}(1 \mathrm{~mL})$. An additional $0.5 \mathrm{~mL}$ of buffer was added and the reactions were incubated for $1 \mathrm{~h}$ at $\mathrm{rt}$ in the dark. After incubation, the solutions were all subjected to dialysis against the buffer for $48 \mathrm{~h}$. The dialyzed solutions were analyzed at $510-550 \mathrm{~nm}$ using a fluorescence microplate reader (excitation wavelength $492 \mathrm{~nm}$ ). The concentrations were calculated as described above. The characterized solutions were then used for cell surface binding experiments.

Cell culture conditions: All cell lines were maintained in a $5 \% \mathrm{CO}_{2}$, water-saturated atmosphere at $37{ }^{\circ} \mathrm{C}$ and media were supplemented with penicillin $(100 \mathrm{unit} / \mathrm{mL})$, streptomycin $(0.1 \mathrm{mg} / \mathrm{mL})$ and $10 \%$ FCS unless otherwise indicated. CHO cells were grown in Ham F12 nutrient mixture. Jurkat cells were grown in RPMI-1640 media.

\section{Cell surface binding of HPA-FITC-conjugated $\mathrm{C}_{18}$-MM-CNTs (Pathway I in Figure 1B):}

Fluorescence Microscopy---CHO Cells were seeded onto glass slides mounted with tissue culture wells (LABTEK) and allowed to adhere for $2 \mathrm{~d}$. The cells were washed 3 times with PBS, and then fixed in 3\% paraformaldehyde in PBS. After three washes, cells were blocked in PBS with 1\% bovine serum albumin for 20 min, followed by the addition of $\mathrm{C}_{18}$-MM-CNT-HPA-FITC complex. After a 1-h incubation at rt in the dark, the cells were washed 3 times. The cells were then mounted using Vectashield with 4,6-diamidino-2-phenylindole (Vector Laboratories). A Zeiss Axiovert 200M inverted microscope equipped with a $63 \times 1.4$ NA PlanApochromat oil immersion lens was employed for imaging. A $175 \mathrm{~W}$ xenon lamp housed in a Sutter DG4 illuminator linked to the microscope by an optical fiber assured shuttering and illumination. Images were acquired using a CoolSNAP HQ CCD camera (Roper Scientific). Slidebook software (Intelligent Imaging Solutions) was used to control the microscope and the camera.

Flow Cytometry---Cells $\left(2 \times 10^{6}\right)$ were seeded in a $10-\mathrm{cm}$ dish for $3 \mathrm{~d}$. The cells were lifted with $1 \mathrm{mM}$ EDTA in PBS, washed, and counted. Flow cytometry analysis was performed on 500,000 cells. The cells were pelleted (3,500 rmp, $3 \mathrm{~min})$ and washed twice with $200 \mu \mathrm{L}$ of PBS containing 1\% FCS. Cells were then treated with HPA-FITC-conjugated $\mathrm{C}_{18}$-MM-CNTs for $1 \mathrm{~h}$ at $\mathrm{rt}$ in the dark. After incubation, cells were pelleted, washed three times and analyzed using a FACScalibur flow cytometer (BD Biosciences).

Titration of binding of HPA to cell surfaces: In order to determine the appropriate condition for complexation of HPA and cells (Figure 1B-pathway II), cells were incubated with various dilutions of HPA-FITC and then analyzed by flow cytometry. The cells were pelleted and washed twice with $200 \mu \mathrm{L}$ of PBS containing $1 \%$ FCS. Cells were then treated with various concentrations of HPA-FITC for $1 \mathrm{~h} \mathrm{at} \mathrm{rt}$ in the dark. After incubation, the cells were pelleted, washed three times and analyzed using a FACScalibur flow cytometer (BD Biosciences). The results are shown below: 


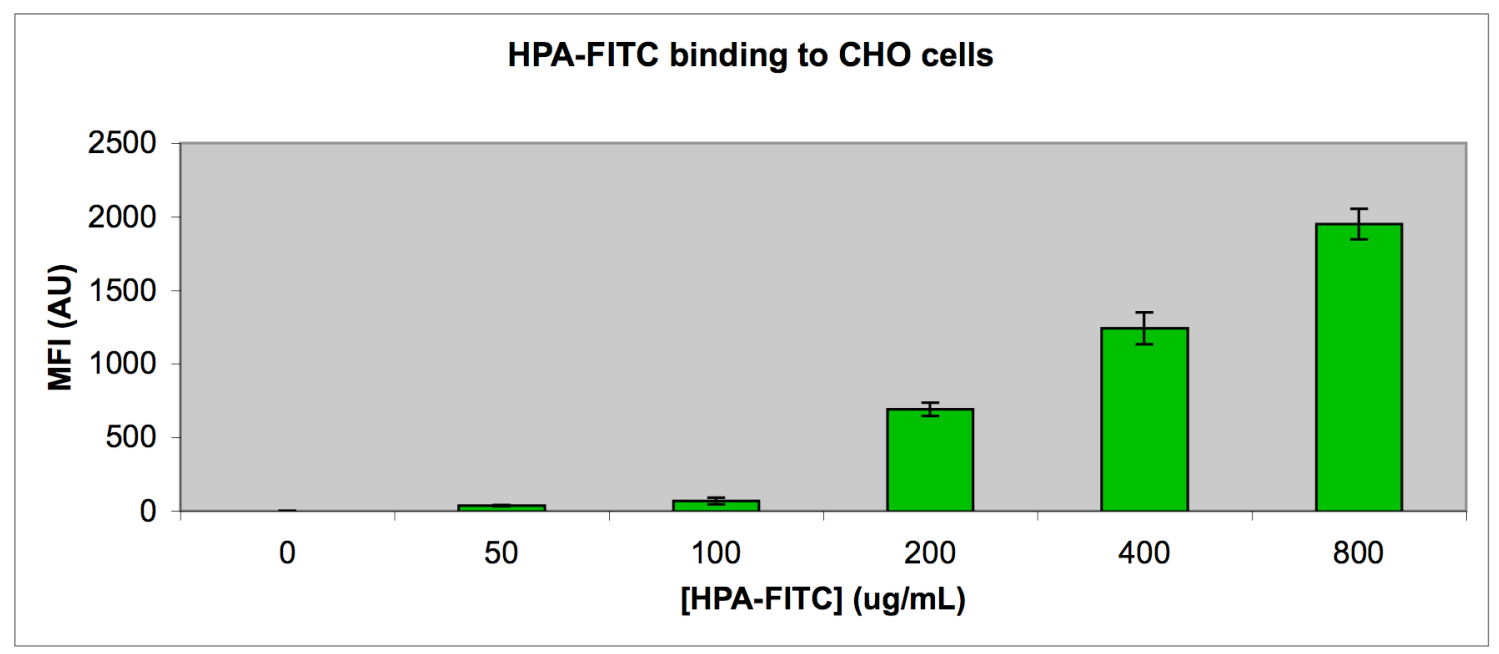

Based on these results, we chose a concentration of HPC-FITC $(400 \mu \mathrm{g} / \mathrm{mL})$ that produced robust cell surface labeling at sub-saturating levels. The assumption was made that free HPA binding sites are still available at this concentration, permitting addition binding to glycopolymer-coated CNTs.

Binding of HPA-coated cells to $\mathbf{C}_{18}$-MM/TR-CNT (Pathway I in Figure 1B): Cells $\left(0.5 \times 10^{6}\right)$ were pelleted $(3,500 \mathrm{rmp}, 3 \mathrm{~min})$ and washed twice with $200 \mu \mathrm{L}$ of PBS containing $1 \%$ FCS. Cells were then treated with unmodified HPA $(400 \mu \mathrm{g} / \mathrm{mL})$ for $1 \mathrm{~h}$ at $\mathrm{rt}$, followed by washing with buffer for 3 times. The cells were then incubated with $\mathrm{C}_{18}-\mathrm{MM} / \mathrm{TR}-\mathrm{CNTs}$ for $1 \mathrm{~h}$ at $\mathrm{rt}$ in the dark. After incubation, cells were pelleted, washed three times and analyzed by flow cytometry.

\section{Cytotoxicity assays:}

CHO cells-Cells were seeded at a density of $1.25 \times 10^{5}$ cells $/ \mathrm{mL}$ and incubated with $\mathrm{C}_{18}-\alpha-\mathrm{MM}-\mathrm{C}_{18}-\alpha-$

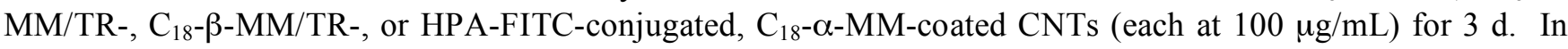
control experiments, the cells were cultured with unmodified CNTs or with media alone. Cells were washed twice with PBS and then trypsinized with $0.25 \%$ trypsin-EDTA (PBS, pH 7.4), resuspended in media and counted every $24 \mathrm{~h}$.

Jurkat cells-Cells were seeded at a density of $1.25 \times 10^{5}$ cells $/ \mathrm{mL}$ and incubated with $\mathrm{C}_{18}-\alpha-\mathrm{MM}-, \mathrm{C}_{18}-\alpha-$

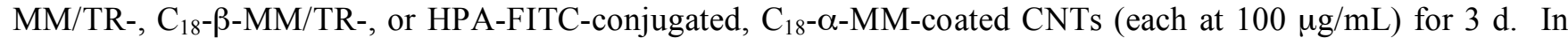
control experiments, the cells were cultured with unmodified CNTs or with media alone. Cells were counted every $24 \mathrm{~h}$. 